\title{
High Dose Interferon Alpha 2a
}

National Cancer Institute

\section{Source}

National Cancer Institute. High Dose Interferon Alpha 2a. NCI Thesaurus. Code C16125.

A treatment approved by FDA for treatment following surgery for melanoma patients

who are at high risk of disease recurrence. (Bypass Budget) 